\title{
The digoxin affair
}

\author{
T. R. D. SHAW \\ B.Sc., M.B., M.R.C.P. \\ St Bartholomew's Hospital, London
}

\begin{abstract}
Summary
The cardiac glycosides are potentially dangerous medicines and consistent preparations are necessary. However, presently used tablets of digoxin differ markedly in the fraction of the dose which is absorbed. Measurement of plasma digoxin levels by radioimmunoassay show that absorption from the Lanoxin brand has varied considerably in recent years due to changes in manufacturing technique. Other brands marketed in the U.K. form a wide range of bio-availability. Hazards to the patient are not entirely avoided by brand name prescribing and it is suggested that new pharmacopoeial standards are needed.
\end{abstract}

\section{Introduction}

Digoxin is the most commonly prescribed cardiac glycoside in the United Kingdom. It is used to slow the heart rate in supraventricular arrhythmias and to assist in the control of cardiac failure: as these are common conditions it is very widely used. It has been estimated that digoxin is currently being taken by over 250,000 patients in this country.

The ratio between effective and toxic doses of digoxin is often low, particularly in patients with myocardial disease. The response of individual patients to digitalis is unpredictable and dose has to be carefully matched to response. Toxicity is associated with an appreciable mortality and morbidity (Beller et al., 1971), but may easily be missed (Lely and van Enter, 1972; Chamberlain, 1972).

In these circumstances it is clearly important that preparations of digoxin should be of consistent potency. It was to achieve this that the purified glycosides digoxin and digitoxin largely replaced the galenical preparations. However, since the introduction of assays for the measurement of plasma digoxin concentrations it has become clear that digoxin preparations in use throughout the world vary widely in potency. It is now known that tablets of digoxin may contain the correct dose but have only a fraction of this dose absorbed by the patient (low 'biological availability'). The average amount absorbed varies from brand to brand and with some brands from batch to batch.

In 1972 there were over twenty different brands of digoxin $0.25 \mathrm{mg}$ BP tablet marketed in the United Kingdom. However, over half of all patients used 'Lanoxin' (Burroughs Wellcome). The problems of biological availability of Lanoxin and of the other brands will be discussed separately.

\section{Changes in Lanoxin bio-availability}

The initial studies with oral digoxin were carried out with a liquid formulation (Wayne, 1933). These showed that digoxin was well absorbed and the average oral requirement was $0.5 \mathrm{mg} /$ day. Tablets of digoxin were first introduced by Burroughs Wellcome and later given the name 'Lanoxin'. Subsequent work on digoxin kinetics usually involved radioisotopes which prevented the use of tablete The introduction of the radioimmunoassay of $f$ digoxin permitted the study of large numbers of patients and normal subjects using commercially available tablets. In work carried out at St Bartholomew's Hospital in 1969 Chamberlain and colleagues (Chamberlain et al., 1970) measured the plasma digoxin levels in patients receiving Lanoxin. Control of atrial fibrillation was associated with levels of 1-2 $\mathrm{ng} / \mathrm{ml}$ and toxicity with levels exceeding $2 \mathrm{ng} / \mathrm{ml}$. Towards the end of 1969 a change, at the time thought unimportant, was made in the production technique of Lanoxin. The original production method was resumed in May 1972, again before the importance of the change was realized. It was subsequently found by Burroughs Wellcome that $\delta$ these changes had greatly altered the absorption of $₹$ the Lanoxin dose (Fig. 1) (Shaw, Howard and o Hamer, 1973). Figure 2 shows the plasma digoxin levels recorded in our department in patients using Lanoxin manufactured during these three periods of $\frac{\sim}{\mathrm{N}}$ time. From 1970-May 1972 low digoxin levels were $ᄋ$ obtained with Lanoxin and many patients had $N$ clinical evidence of underdigitalization. The bio- N logical availability of Lanoxin was reduced during ${ }^{O}$ this period. Before the first production change and after the return to the original process, absorption $\frac{0}{\infty}$ of digoxin was nearly complete. The newer Lanoxin $\stackrel{\infty}{\rightarrow}$ can be used at traditional doses.

When the effect of the latter alteration in Lanoxin production was detected it was decided to recall 


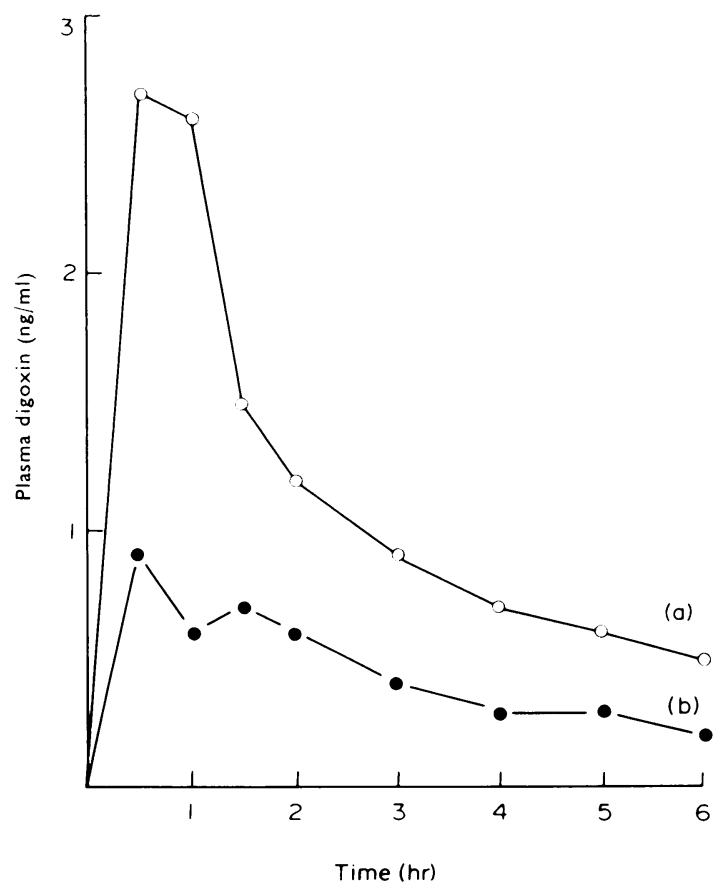

Fig. 1. Absorption curves recorded in a normal subject after a $0.5 \mathrm{mg}$ dose of Lanoxin manufactured (a) after the change of May 1972 (newer Lanoxin) and (b) shortly before this second alteration in production method (older Lanoxin).

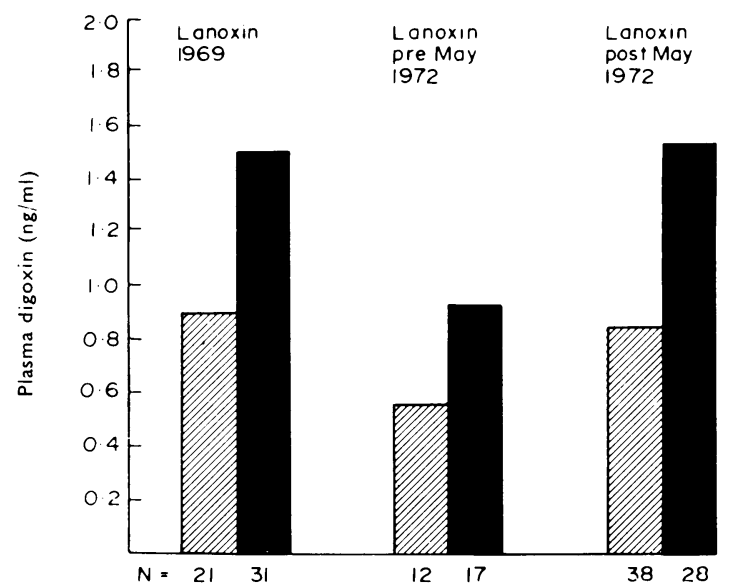

FIG. 2. Mean plasma digoxin levels recorded in patients using Lanoxin. Striped boxes, 0.25-0.375 mg/day, black boxes, $0 \cdot 5 \mathrm{mg} /$ day. All patients had a blood urea $<40 \mathrm{mg} / 100 \mathrm{ml}$. $\mathrm{N}$ number of patients in each group.

stocks of tablets made before May 1972 and to inform doctors and pharmacists of the change (British Medical Journal, 1972; Lancet, 1972). Because of the increase in the amount of digoxin absorbed pharmacists were advised by the Committee on Safety of Medicine and the Pharmaceutical Society to dispense Lanoxin only when it had been specified (Pharmaceutical Journal, 1972). Unfortunately many practitioners were unclear of the effect of the change, and press reports suggested that the latest Lanoxin was 'superpotent' (Daily Express, 1972; Daily Mirror, 1972; The Times, 1972). As a result many doctors and pharmacists have avoided Lanoxin or use it in unnecessarily small doses.

\section{Bio-availability of other brands}

In patients using other brands of digoxin tablet in the period January-June 1972, plasma digoxin levels were similar to those obtained with the 'older', pre-May 1972 Lanoxin (Fig. 3). In some individual cases the older Lanoxin had produced higher levels than other brands (Shaw, Howard and Hamer, 1972). The mean levels found with the group of other brands' is influenced both by the bio-availability of individual brands and by the frequency with which each brand was used. Most of the commonly used brands resembled the older Lanoxin. The differences in older and newer Lanoxin had been paralleled by changes in the in vitro dissolution rate of the tablets (Fig. 4). The dissolution rates of most of the other brands available in Britain approximate that of older Lanoxin but some dissolve as rapidly as the newer Lanoxin (Beckett and Cowan, 1972, 1973; Shaw 1973). This strongly suggested that the other brands were far from equivalent in efficacy. This non-equivalence has been confirmed by studies on individual brands chosen to represent a range of dissolution rates (Shaw et al., 1973b) and is illus-

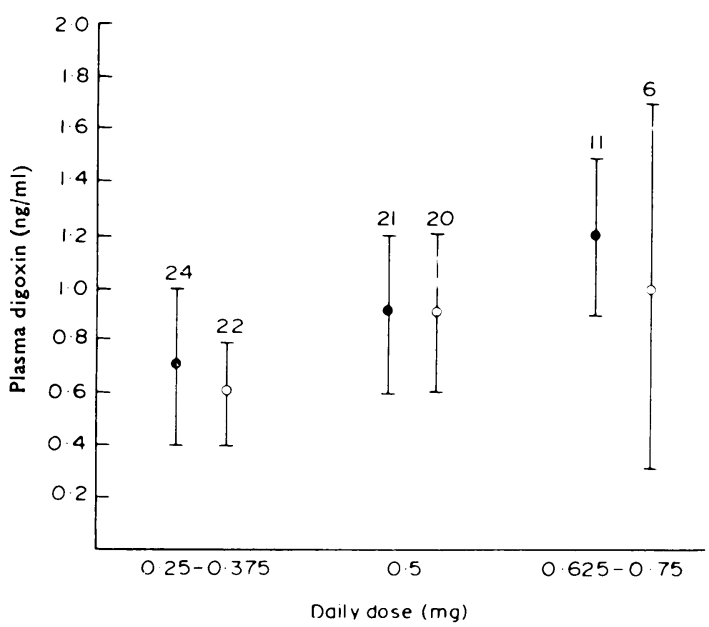

Fig. 3. Plasma digoxin levels (mean s.d.) in patients using older Lanoxin and a combined group of other brands. The numbers within the figure give the total patients in each group. Lanoxin; $\bigcirc$, other brands. 


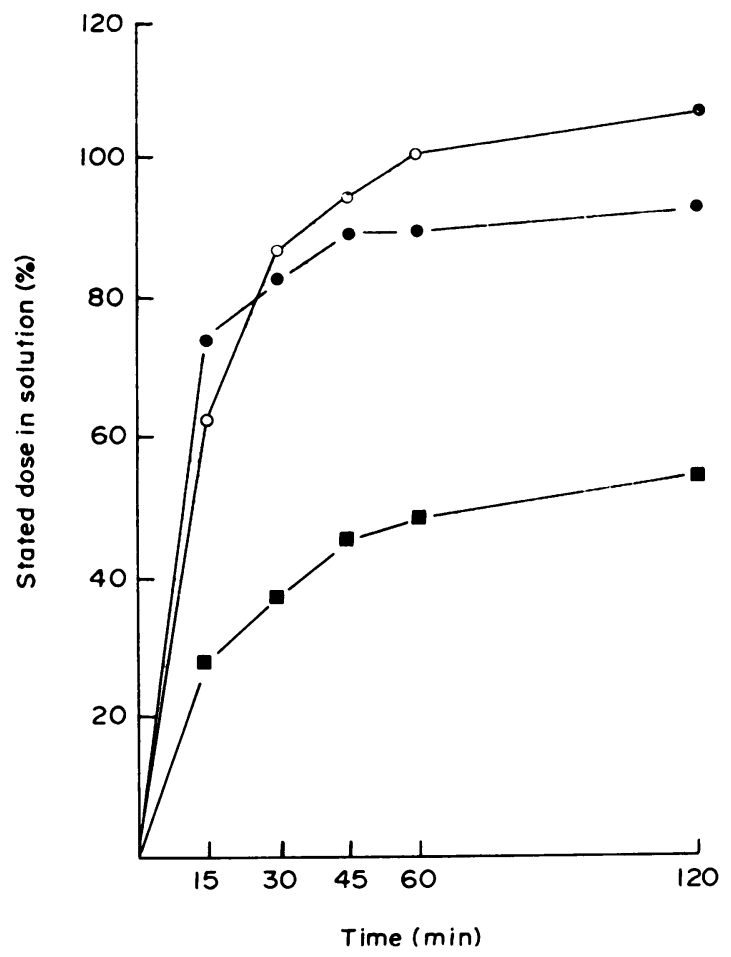

Fig. 4. Dissolution rates of older (a) and newer Lanoxin $(O$, mean values of three estimations) and of Lanoxin manufactured prior to 1969 (O, mean of two estimations).

trated by Table 1 which shows the plasma levels, clinical response and dissolution rate found with four types of tablet administered at constant dosages to a group of thirteen patients with atrial fibrillation.

In addition some brands show startling variation in dissolution rate from batch to batch (Fig. 5). Enquiries have shown that other companies have modified their production method in recent years.

The variation between brands appears to be due to the effect that different production methods have on the digoxin particle size (Shaw et al., 1973a).

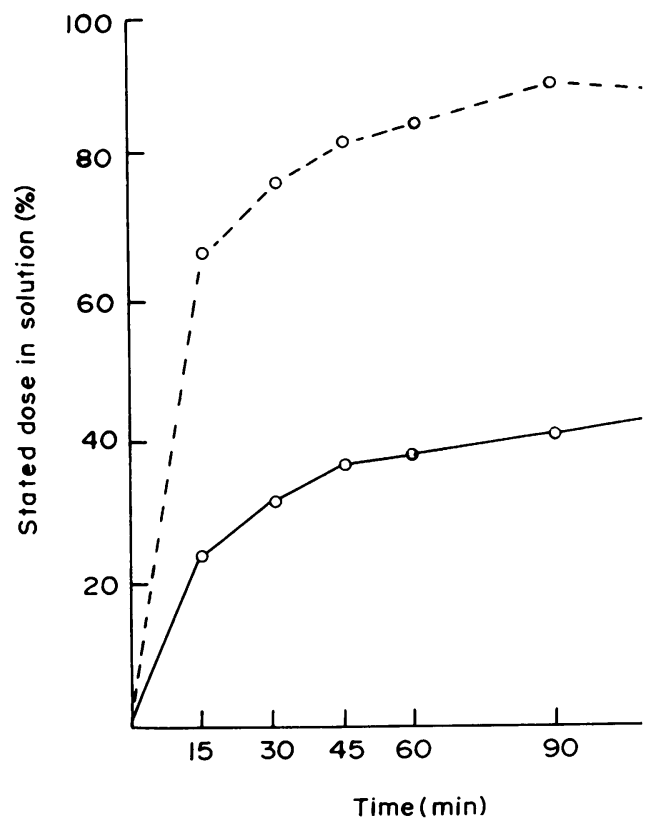

Fig. 5. Dissolution rates of two different batches commonly used British brand. Broken line, batc solid line, batch 2 .

Difficulties in digoxin treatment due to varial biological availability

The present non-equivalence of digoxin 1 creates distinct hazards during therapy. If a $\mathrm{r}$ is given standard dosages of poorly absorbed 1 then he is likely to have inadequate digoxin and will remain underdigitalized. If larger dos given to achieve a clinical response then to may occur if he later receives tablets which al absorbed or if he is changed to parenteral dos

The clinical situation is made more comp the very marked differences in the way that indi patients respond to a change from slowly diss to quickly dissolving tablets (Fig. 6). There safe fixed ratio of dose equivalence for di brands.

TABLE 1. Plasma digoxin levels and resting ventricular rates achieved in thirteen paitients with atrial fibrillation who used four types of digoxin tablet of different in vitro dissolution rate. Daily dosage was constant for each patient throughout

\begin{tabular}{ccccc}
\hline Brand & $\begin{array}{c}\text { Newer } \\
\text { Lanoxin }\end{array}$ & Nativelle & Boots & $\begin{array}{c}\text { Older } \\
\text { Lanoxin }\end{array}$ \\
\hline $\begin{array}{c}\text { Plasma digoxin level } \\
\text { (mean } \pm \text { s.d.) }\end{array}$ & $1 \cdot 36 \pm 0.56$ & $1 \cdot 28 \pm 0 \cdot 50$ & $1 \cdot 10 \pm 0.4$ & $1 \cdot 00 \pm 0.47$ \\
$\begin{array}{c}\text { Resting ventricular rate } \\
\text { (mean } \pm \text { s.d.) }\end{array}$ & $74 \cdot 9 \pm 17 \cdot 1$ & $79 \cdot 1 \pm 16.6$ & $83 \cdot 7 \pm 16.8$ & $84 \cdot 5 \pm 19 \cdot 2$ \\
$\begin{array}{c}\text { Percentage of stated dose } \\
\text { in solution at } 30 \text { min }\end{array}$ & 86 & 57 & 32 & 37 \\
\hline
\end{tabular}




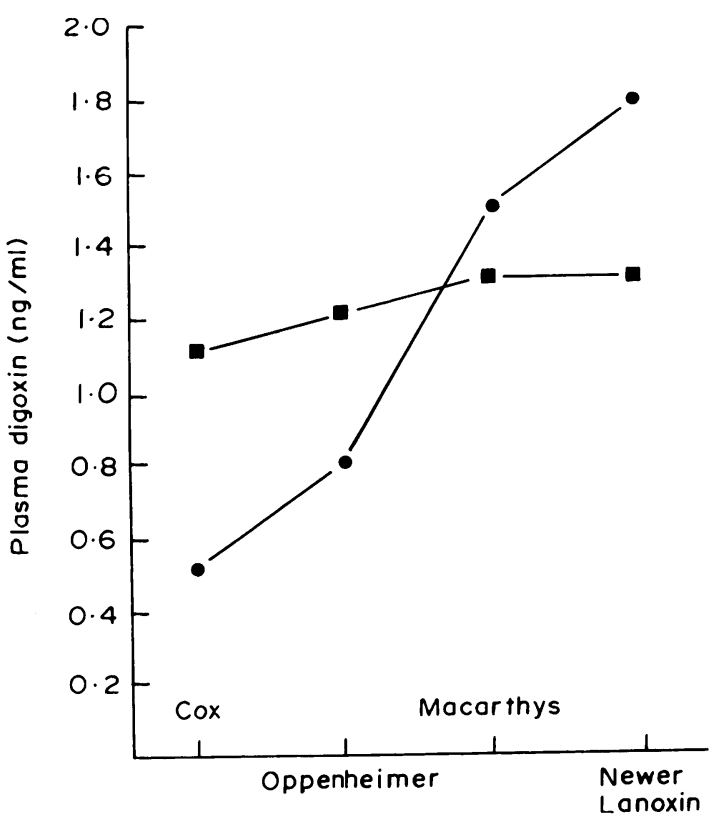

FIG. 6. Plasma digoxin levels recorded in two patients who used four brands of digoxin at a constant dosage of $0.5 \mathrm{mg} /$ day.

\section{Is brand name prescribing helpful?}

Brand name prescribing of digoxin can reduce the hazards to the patient in the present chaotic situation but is far from being an adequate solution to the problem, for the following reasons. (1) Some brands vary widely from batch to batch; (2) it is extremely difficult to discover the brand which the patient is currently using. Most people do not bring their tablets to the clinic and for the few who do the brand frequently cannot be identified. Even when the pharmacist is contacted in a third of instances he has recently used more than one supplier of digoxin; (3) on occasions pharmacists have not dispensed the brand requested; (4) there are too many brands presently available.

I would suggest that the only satisfactory solution is for all available digoxin tablets to be of equal efficacy and with a dissolution rate which ensures full absorption of the digoxin dose. Although special slow release formulations are useful for some drugs, they are not helpful in the case of digoxin, since absorption of digoxin is precarious and clinical response is not intimately related to the transient high blood levels which occur during absorption. Fortunately it appears that the dissolution rate test will enable all digoxin tablets to be uniform in potency (Lindenbaum et al., 1973; Johnson et al., 1973). It would then be the job of the doctor to prescribe the medicine and the job of the pharmacist to ensure that effective formulations of it were dispensed. For the pharmacist the brand name would still be a convenient reflection of the services and quality control methods of the individual manufacturers.

\section{References}

Beckett, A.H. \& Cowan, D.A. (1972) Digoxin problems. Pharmaceutical Journal, 209, 174.

BecketT, A.H. \& Cowan, D.A. (1973) Differences in the dissolution rate of generic digoxin tablets. Pharmaceutical Journal, 211, 111.

Beller, G.A., Smith, T.W., Abelmann, W.H., Haber, E. \& HooD, W.B. (1971) Digitalis intoxication: a prospective clinical study with serum level correlations. New England Journal of Medicine, 284, 989.

British Medical Journal (1972) Dosage of Digoxin, 3, 427.

Chamerlain, D.A., White, R.J., Howard, M.R. \& Smith, T.W. (1970) Plasma digoxin concentrations in patients with atrial fibrillation. British Medical Journal, 3, 429.

Chamberlain, D.A. (1972) Problems of digitalis overdosage. Prescribers Journal, 12, 84.

DaILY EXPRESS (1972) August 2nd.

DaILy Mirror (1972) August 2nd.

Johnson, B.F., Greer, M., McCrerie, J., Bye, C. \& Fowle, A. (1973) Rate of dissolution of digoxin tablets as a predictor of absorption. Lancet, i, 1473 .

LANCET (1972) The bio-availability of digoxin. ii, 311.

Lely, A.H. \& VAN ENTER, C.H.J. (1972) Non-cardiac symptoms of digitalis intoxication. American Heart Journal, 83, 149.

Lindenbaum, J., Butler, V.P., Murphy, J.E. \& Cresswell, R.M. (1973) Correlation of digoxin-tablet dissolutionrate with biological availability. Lancet, i, 1215.

Pharmaceutical Journal (1972) Lanoxin potency doubled, 209, 133.

Shaw, T.R.D., Howard, M.R. \& Hamer, J. (1972) Variation in the biological availability of digoxin. Lancet, ii, 303 .

SHAw, T.R.D. (1973) The bio-availability of digoxin tablets. In: International Symposium on Digitalis (in press).

Shaw, T.R.D., HowARD, M.R. \& HAMER, J. (1973a) Recent changes in the biological availability of digoxin: effect of an alteration in Lanoxin tablets. British Heart Journal (in press).

Shaw, T.R.D., Carless, J.E., Howard, M.R. \& Raymond, K. (1973b) Particle size and absor ption of digoxin. Lancet, ii, 209.

Shaw, T.R.D., Raymond, K., Howard, M.R. \& Hamer, J. (1973c) Therapeutic non-equivalence of digoxin tablets in the United Kingdom: correlation with tablet dissolution rate. British Medical Journal (in press).

The Times (1972) August 2nd.

WAYNE, E.J. (1933) Clinical observations on two pure glucosides of digitalis: digoxin and digitalinum verum. Clinical Science, 1, 63. 


\section{Discussion}

Dr F. Hartley wondered whether it was a reasonable assumption from the data that the more rapidly a digoxin tablet is dissolved, judged by the in vitro testing, the more likely it is to give constancy of therapeutic action. Since this could lead to disastrous results if the drug was too rapidly absorbed, he also wondered whether a desirable range of dissolution rates could be established and whether there should be two categories of digoxin, one for rapid use when a rapid action is required, and the other for less urgent situations.

Dr Shaw said that rapidly dissolving tablets were to be preferred for several reasons. He quoted the use of rapidly absorbed liquid formulations of digoxin in children without apparent hazard and reported studies of very rapidly absorbed digoxin tablets in adults, which produced on occasions nausea and vomiting in normal fasting volunteers but seldom in patients.
Professor A. H. Beckett's experience was that in a quick-releasing digoxin tablet from a reputable manufacturer, batch to batch and tablet to tablet variation was small.

Dr. A. Herxheimer found Dr Shaw's data in support of the argument for restricting the number of available sources of digoxin; it does not seem to be in the public interest for so many varieties to be available. He suggested that the pharmaceutical industry should find some means of achieving this, surmising that the industry would not welcome outside participation in such a regulatory process. Dr Shaw preferred to hope that either a government agency or the pharmaceutical companies would ensure that all tablets were equally bio-available, in which event, the number of sources would cease to matter.

Mr F. Allen, Chief Pharmacist at Whipps Cross Hospital, suggested a return to Digitalis leaf. 